\title{
Copyright Law and Online Journalism in Bangladesh: The Lights are on, but Nobody is Home
}

\section{Md Saiful Alam Chowdhury ${ }^{1 *}$ and Md Waseq Ur Rahman ${ }^{2}$}

${ }^{1}$ Department of Mass Communication and Journalism, University of Dhaka, Dhaka-1000, Bangladesh

${ }^{2}$ Independent Researcher, Bangladesh

\begin{abstract}
Bangladesh is one of the next eleven countries in the world with approximately 160 million people is experiencing a great boom in the growth of online news portals in the recent past due to the development of wireless communication technologies. The seemingly ease of online content production has been an integral perspective leading to the mushrooming of online news portals all over the country burgeoning a culture of substandard journalism. Lack of enforcement regarding the protection of intellectual properties is fueling this trend. Extremely weak to almost no copyrights protection system of Bangladesh has been victimizing every sector. It has been a stemming factor hindering innovation and creativity in the path to economic development of the nation. Without proper regulatory policies, newer technologies are adding to the wound. In this perspective, as an explanatory article, this paper analyzed the present situation of the online media portals of Bangladesh that sought out to literature focusing on copyright issues on other industries. This article stands its ground by the observations of the various cases of infringements and their implications on the entire industry.
\end{abstract}

Keywords: Copyright law; Copyright infringement; Intellectual property rights; Online news portal; Online journalism

\section{Introduction}

As the global media is taken over by the emergence of super fast communication technologies the model of 24-hour news cycle of the traditional media has given the audience or readers' demands of as soon as it happens news. The traditional model of journalism has been facing an immense challenge in the race against the immediacy factor as new communication technologies as well as the internet has changed the structure of journalism radically. Although online media in more developed countries has managed to cope up with the demands of the future, developing nations are still thriving to adapt with the advents of new technologies. Online journalism in Bangladesh is not lagging behind regarding utilizing the advents to the fullest. Traditional news media have been conscious of integrating online outlets to keep up with the digital race. In fact, the race is pretty intense as all major media now exist in offline as well as online platforms including their social media counterparts.

However, the challenge for the industry remains in terms serving accurate and original content online. The seeming ease of setup and management of online portals has led to the flourish of sub-standard online news portals in the domain of Bangladeshi news media. The deviation of standards ranges from breaking misleading information to copying information from the other sources. Referencing foreign news media to report global news has been a long standing tradition of the mainstream newspapers. However, now there exist numerous online news portals who are copying information from foreign as well as local sources to the word, as a carbon copy. Notwithstanding questioning the core motif of why such portals even exist it is an issue of major violation of copyrights.

Numerous such violations are taking place everyday yet only a handful cases are leading to litigation. Foreign media are reacting with more pragmatic measures of taking down copied contents through official complaints. Although the western media have a strict policy on plagiarism, leading to dismissals of renowned journalists [1], media in the developing nations are facing a major hurdle controlling as well as responding to such issues. This article observes some selected incidents of plagiarisms in the online news portals and endeavors to paint a critical picture of the situation.

\section{Scope and Method of the Study}

To present a portrayal of the situation of copyrights in the online news media in Bangladesh reviews several types of research related to intellectual property rights in Bangladesh and analyzes several cases where the question of copyrights violation was raised. The selection of the cases is deliberate. The incidents analyzed here have been found reported in various online news media, social media, and blogs. For authentication, only cases that were verified by the authors were selected. For a couple of cases found in random search for allegations of copyright violation, the Digital Millennium Copyright Act (DMCA) database was looked into.

At least 5 cases were selected for analysis after verification and collection of proof by the authors. There are infinite numbers of probabilities of copyright violation that are possible. The selected cases are somewhat representative of the most common allegations found online (Table 1).

\section{Copyrights in Bangladesh}

As an agrarian nation, since a long time before the birth of Bangladesh, the key economic activity was based on agriculture and farming. With extremely high population rate hand in hand with extremely low literacy rate, only a handful of people were

*Corresponding author: Md Saiful Alam Chowdhury, Department of Mass Communication and Journalism, University of Dhaka, Dhaka-1000, Bangladesh, Tel: +4560901012; E-mail: chowdhuri2001@yahoo.com

Received February 01, 2017; Accepted March 03, 2017; Published March 10 2017

Citation: Chowdhury MSA, Rahman MWU (2017) Copyright Law and Online Journalism in Bangladesh: The Lights are on, but Nobody is Home. Intel Prop Rights. 5: 179. doi: 10.4172/2375-4516.1000179

Copyright: @ 2017 Chowdhury MSA, et al. This is an open-access article distributed under the terms of the Creative Commons Attribution License, which permits unrestricted use, distribution, and reproduction in any medium, provided the original author and source are credited. 


\begin{tabular}{|c|c|c|c|c|c|}
\hline Case & Original by & Date of original & Republished by & Date of republish & Copied content \\
\hline 1. & Bdnews24 & August 2016 & Ittefaq Online & August 2016 & Photos \\
\hline 2. & Dhaka Tribune & 13.09 .16 & Bangladesh Pratidin Online & 15.09 .16 & Text \\
\hline 3. & Amardesh & 21.06 .15 & Deshebideshe & 13.10 .15 & Photo and Text \\
\hline 4. & Ittefaq Online & 14.03 .17 & News24 & 14.03 .17 & Photo and Text \\
\hline 5. & Banglanews24 & 01.01 .17 & Futurenews24, Daily Vorerpata, Sandwipnews, Daily Noboalo, & 01.01 .17 & Text \\
\hline
\end{tabular}

Table 1: List of cases analyzed for this paper.

enabled to engage in scientific research or technological innovations actively. Amidst the political turmoil and fatal natural disasters, the understanding the necessity of intellectual property for overall economic development remained in the dark. As a result, there were little to no acknowledgment of the right to intellectual property be it in the economic sector or cultural. Thus, piracy became a widespread phenomenon and widely accepted by the masses because it enabled them to buy books, music, and a variety of other products at a lower price [2]. The vast difference in the inventor to consumer ratio in Bangladesh worsened the conditions for creativity and innovation to breed, let alone the protection of it. Only when the nation began seeing incredibly high economic growth and foreign investment demands of protection of innovation Bangladesh began to realize the major hurdle in the path to prosperity.

According to an assessment by the World Intellectual Property Organization on the National Intellectual Property System of Bangladesh, until the end of the millennium Bangladesh continued some form of the legal framework passed on by the British Empire on intellectual property rights followed by an amalgamation of already existing laws regarding copyrights was promulgated in 1962 as the copyright ordinance which was later administered up to enact the Copyright Act, 2000 and further amended in 2005 [3]. The assessment includes a chronological record of Bangladesh complying with the world standards of intellectual property rights protection.

Bangladesh participated in the convention establishing the World Intellectual Property Organization (WIPO) on May 11, 1985. Bangladesh became a member of the Paris Convention for the Protection of Industrial Property in 1991 and of the Berne Convention for the Protection of Literary and Artistic Works in 1999. Bangladesh is a signatory of the Trade-Related Aspects of Intellectual Property Rights (TRIPS) agreement of the World Trade Organization (WTO), which came into force on January 1, 1995 [3].

Signing the conventions mentioned above and international treaties the Government of Bangladesh was a legal obligation to develop and implement intellectual property rights to help protect creative ownerships of the artists, musicians, writers, publishers, filmmakers, producers, and software developers [4] By the Section 82(1) of the Copyright Act 2000, the maximum punishment for violation of copyrights in Bangladesh for a first-time offender is four years of imprisonment and a monetary fine of up to BDT 200,000 which is equivalent to approx. USD \$2500 [5]. However, according to the computer programmers and software developers in Bangladesh the Act does not prohibit songs, writing or computer programs from being reproduced without permission for non-commercial purposes [4]. Suffice it to say present legal framework, as well as administrative setup, is inadequate to provide expected protection of intellectual property [6].

Alongside various loopholes within thelaws regarding the protection of the intellectual property rights there exists an even bigger problem of monitoring the enforcement of these laws. There exist pragmatic obstacles relating to the management of the processes regarding the providing protection to all the citizens. The reality is until the year
2009, no firm from Bangladesh had ever applied for IP protection in abroad, and 7000 patent applications, 6000 design applications as well as 80,503 trademark applications of the 144,706 received since 1971 remained pending [3]. Despite the laws, Bangladesh is still not adequately equipped to manage the mere application process, and there remains to protect these copyrights holders from infringement.

The impracticality, for companies to seek permission for every piece of copyrighted work they use from individual copyright holders and for authors to monitor and negotiate the rights to their work with parties interested in using it, demands the establishment of copyright societies or a collective of copyright management [7] as a third party to monitor and mediate on behalf of the authors and users alike. There exists Intellectual Property Association of Bangladesh that is endeavoring to provide services to its members through digitally enhancing the procedures of protecting individual property rights. However, according to their website the association has only 79 individuals and 43 corporate members [8].

\section{Existing Research on Copyrights Law in Bangladesh}

Protection of intellectual property rights in Bangladesh is still a developing nation issue. Only with recent economic growth, the importance of establishing a culture of protection of IP rights has received any substantial attention in Bangladesh. For instance, the handful of articles found on the issue is less than ten years old. These papers are mostly overviews of the Intellectual Property Rights situation in Bangladesh. The common methodology employed for all of these explorations are analyzing existing government IP policies and the legal framework of protecting IP rights. Some conducted survey interviews and analysis of court cases proceeding related to copyrights infringements. Alongside presenting the existing intellectual property rights situation in Bangladesh, the common ground all of this literature make it to is highlight the importance of appreciation for individual/ communal intellectual property to facilitate innovation and creativity to accelerate economic growth. Recommendations from these papers focus on the necessity of a comprehensive policy that helps enforce copyright laws effectively as well as promote a culture of reverence towards IP rights.

In an assessment of National Intellectual Property [3], discuss the challenges and priorities of the main issues related to Intellectual Property Rights administration, law enforcement and future of IP generation and commercialization. Under the guidance of the World Intellectual Property Organization (WIPO), the paper bases its discussion on survey interviews with national IP office officials, IP lawyers, industry officials, NGO promoting IP awareness, and academics on the versatile range of subjects regarding the intellectual property industry. The paper statistically outlines the economic condition of Bangladesh within a historical context and then goes on to identify the features of the existing intellectual property right system, service delivery infrastructure, common practices, priority sectors and key stakeholders. The assessment is complemented with a set of recommendations on focused for an IP right system substantial to national development goal. 
Hawlader [7] highlights the long-lasting economic implications of strong IP rights system and exemplifies the possibilities for a developing nation such as Bangladesh presenting an analysis of cases of nations who successfully implemented an efficient IP rights system. The chapter analyzed cases of measures implemented by developed countries to establish IP rights protection in respective countries and how those lead to the growth of the economies exponentially. The key focus of the chapter is outlining potential measures of enforcement of copyrights laws effectively for in the context of developing the economy. The recommendations prescribed stands on the grounds of the comparative analysis of the Bangladeshi economy with other developed nations.

Naznin [6] analyzes case studies of litigations of copyright violations to argue that although the existing laws could be effective enough to bring justice for infringement victims however the infrastructure for copyright protection is not nearly adequate in Bangladesh. In the most recent overview of the IP rights situation in Bangladesh [2] discusses the international compliance measures implemented in Bangladesh in the recent years and demonstrates the roles of various agencies in ensuring enforcement of copyright laws. The paper prescribes mass awareness initiatives to popularize the importance of copyrights and public-private partnership collaborations with trade organization to enforce stricter industry compliances. Hossain [8] focuses in his article on the present situation of copyright protection in Bangladesh and the level of implementation of the laws.

Due to the lack of research on copyright issues in the online news media of Bangladesh this article resorted to sought out to newspaper articles and online resources.

\section{Present Scenario of Online Journalism in Bangladesh}

The practice of internet-based journalism in Bangladesh formally began in 2006 as the first website in Bangladesh dedicated to the only news was www.bdnews24.com. The first of its kind had sufficient investment to focus on good practices of journalistic approach. The two factors that scaffold the rise of popularity of the site was it had the first mover's advantage of playing in a zero competition market and also for the first time it afforded the Bangladeshi people with 24-hours of news as it took place. Mobile versions of the site allowed users to get news on the go. Bdnews 24 also sold text message subscriptions that sent users news updates via text. News delivery for Bangladesh was truly revolutionized.

Growing popularity of the medium, let competition to follow, and they all followed the footsteps of their predecessor. The second ever online news portal in Bangladesh was www.banglanews24.com. As it happened, investors understood the importance of the 24-hour news service to the Bangladeshi audience, thus having "news24" or at least " 24 " in title became an industry standard. After that followed, many others such as www.bart24.com, www.risingbd.com and so on.

As the agiotage of online news media began, mainstream newspapers started joining the race. They already had the journalistic know how's, established news publishing processes and pool of reporters at their disposal. They simply launched an online version, and that was a pivotal point for news reporting in Bangladesh as the 24-hour news cycle had officially been abolished and replaced by the news as soon as it happens format. Some of the strategies implemented by the mainstream newspapers to adapt to the new format were very innovative. To serve the mass of online audience one of the newspapers launched a digital copy of their daily in which instead of turning a page the viewer only required a click to do so. One other newspaper started doing video news coverage on their site for important events and special features. Soon enough television channels also joined the force with dedicated YouTube channels to broadcast their video news reports.

With the spread of Facebook throughout the nation, the online news portals took to the social media to extend their reach. With dedicated social media teams working 24-hours, news links were shared as soon as they were uploaded. The social media platform allowed the online news media to promote them in the cyberspace actively. The concept of interactivity and hypertext within the field of online journalism were put to work at full throttle by the social media teams. Not only did they post news links as soon as it was published, but they also published morning briefings, repeatedly shared important and featured stories and actively moderated the discussions in the social media.

One of the most significant implications of the emergence of the online news media was the creation of an online database of information and content available for viewing from anywhere, anytime and by anyone with an internet connection. With the rise of the use of online information unfolded versatile range of challenges. The fierce competition of being the first to break the news saw the demise of fact checking and ensuring credibility. The contest of getting more clicks and views on the site brought back the tabloid-like sensationalism in the online news. Low cost of publishing [9] led anyone and everyone with a website to become a journalist, and as a result, substandard quality of journalism bloomed. It was also the first time Bangladesh was uploading online content in high frequency which led to an unprecedented crisis of protection of intellectual property of the online content.

\section{Practices Violating Copyrights in the Online News Media}

The common practice in many of the online news portals in Bangladesh of republishing news articles where the main contents remain substantially similar regarding form and structure is directly in violation of the copyrights of the original author. In the cases analyzed the original contents were published at the expense of the author's' time, resources, energy and money on the part of the portal that published the content. Considering the sample cases and review of various other literature related to the online news portals of Bangladesh the study found various common patterns of copyright violations.

Along the side lack of enforcement of the copyright law of Bangladesh as in almost all other industries (books, music, etc.) there exist certain tendencies of violating copyrights that are founded in the very nature of the online news media industry. The existence of certain online media without any legitimate journalistic base to offer objective news reporting is affecting the appropriate dynamics of the industry to function.

Following is a reflection of the violations of intellectual property rights faced by original publishers.

\section{Most Frequently Copied News}

There are particular types of news that are most commonly copied. It is the nature of these kinds of news that allows the copying to be relatively less risky, lucrative regarding gaining public attention and spreading political propaganda.

1. Breaking news on sensitive Issues 
2. Entertainment news, specifically international news

3. Political news with subjective motifs

4. News that are based on rumors

\section{Unfair Play in the Race against Time}

It is evident that the emergence of the online news media in Bangladesh has broken the traditional news cycle as like other parts of the world. With online portals, reporters are now enabled to report news as soon as it happens often broadcasting events live. However, it also shortens the timeline within which the reporter has to gather the news, double check or cross-check the facts, write and publish it. With so many media now the competition is fierce to break or publish the news ahead of everyone.

The race for publishing news while it is already fresh has been a key challenge for journalists in the online news media in Bangladesh. Journalists often fail to report news within the time crunch. As a result, some portals can break the news while it is still news while others fail to make the cut. However, editors are disinclined to accept this failure. They simply let a sub-editor copy the news from the others and publish it as their own instead of citing a source for the information. This is a major violation of copyright on the part of the media. While it might keep them in the race for the time being, but they set an awful standard for the journalists working for them, indirectly provoking them to lie, cheat or steal their way to the top. In this perspective, media are not only in infringement of copyright laws but also defying the ethical boundaries as a journalist.

As expected, major online news portals have become major names because of the resources they allow to meet the demand of the medium, fast and accurate journalism. Many others, including the online versions of highly circulated major dailies, are still in the transformation phase from the 24-hour cycle and resort to copying content from another portal when they are faced with balancing the inadequacy of resources and lack of efficiency of required running an online news portal. With the enforcement of the copyright, such violations could be very expensive and potentially disastrous for a news media in terms earning a bad reputation.

\section{Use of Photos and Illustration}

Covering news comes at a cost. International events are at the top of the list. Also, the large number of events taking place all around the country makes it expensive to have reporter's at all geographical locations. There are news agencies that sell licensed photos and videos to the news publishers and broadcasters. Mainstream online news portals often invest in covering big international events to publish exclusive content. Most major sites resort to buying photos and illustrations from other agencies. Others are resorting to simply downloading them from the original publisher and putting them up on their pictures. Both get equal attention while one pays for the original content. Unlawful use of others photos most frequently occurs in the entertainment and international news.

In a recent incident, one of the major online news portals has tried to remedy this situation by publishing a public notice and warning against the offender to take legal actions [10]. The offender published the licensed photos from the original publisher and used it in their version of the news without citing any sources or seeking permission from the original publisher (Figure 1). This is a violation of the original author's rights over his investment in terms of time, finance and skills (Figure 1).

From the five cases analyzed appropriation of photos without

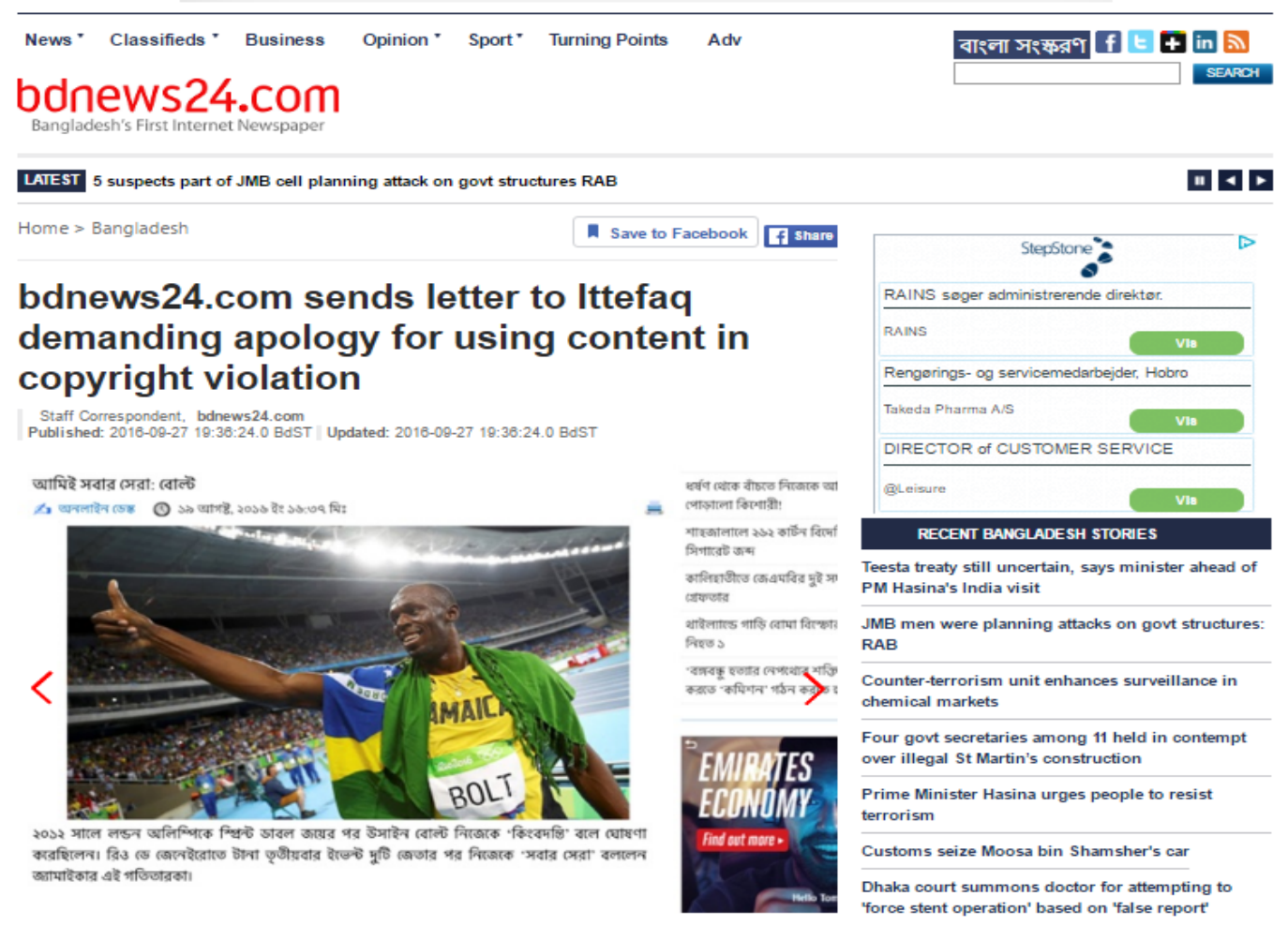

Figure 1: Bdnews24.Com has accused Ittefaq 
permission or citation along with other content occurred at least thrice. This comes under the violation of the Copyright Act 2000 of Bangladesh, and the offender could face major legal actions that include imprisonment and a hefty fine. However, lack of enforcement of the law has left the publishers with nothing to do more than file for a takedown notice to the Digital Millennium Copyright Act or contact the copyright violator directly to take the content down from the site.

\section{Including wrong information from the original}

The three types of news most commonly copied from other media, entertainment news, political news with subjective motifs and news that are based on rumors often fall into this trap. In the process of copying information from other sources, they include the wrong information as well. This not only grounds for copyrights infringement but also a major violation of public trust by spreading wrong information. The $4^{\text {th }}$ case analyzed in this study copied news from about a foreign film industry. The original publisher exaggerated a bit of information about a relevant financial matter which was inaccurate. The copied news included the same figure with the same miscalculation.

As journalism depends only on accuracy, precisely $100 \%$ accuracy, checking for wrong information is a basic journalistic approach to reporting news. For thriving news portals without appropriate resources, basics are dissolved in the necessity to publish. Information that is potentially scandalous and might generate public interest is being issued by these pseudo media portals to increase the number of visits to their sites. Politically motivated news and news based on rumors are often the ones that include misinformation. When copied by others it not only affects public perception but also breaks the standard practices of objective journalism for the reporters and sub-editors responsible for publishing the news.

\section{Many News Sites, One Report}

The pseudo news websites are copying all mainstream online news portals. These pseudo sites lack investments regarding the journalistic process, finance, and reputation. Many do not even have reporters, only a couple of employees paid to copy paste content from other major news sites. Feeding on the hard work of real reporters these pseudo sites survive on other sources for daily news content and once in a while try to make it big with sham or scandalous news, which devalues the entire industry's worth of quality news reporting.

In the fifth case, a google search with the headline as the key returns five links to 5 different news sites. Only one of them is the original publisher. Plagiarizing word to word is the most ferocious violation of intellectual property rights. News sites who are surviving on plagiarism deprive the publisher of the news portal that is publishing the original content and the reporter who is writing the report on the right to ownership of the intellectual property (Figure 2).

The situation worsens when many news sites copy the same headline, news, and photos from one single source and publish it as their own. This way numerous sites could be found online with the same news with same headlines, body, and photos.

\section{Recommendations and Suggestions}

The initial success of the major online news media and the increase in internet users had led to mushrooming of various online-based news portals in Bangladesh. According to a news article, approximately 1700 applications for registrations of local and national online news portals were filed from all over the country after the government passed a law for mandatory registration of online media to check the deterioration of the standards of news publishing in the online medium [11]. Even if one-fifth of the number of applications existed in reality protecting copyright for each piece would become a major hurdle in the current capacity of the copyright offices of the country. Although the government is launching newer initiatives to address the critical situation and there are several laws in a position to regulate the online news media, this is not nearly enough in contrast to the growth rate of the industry. Additionally, continuous development of newer features
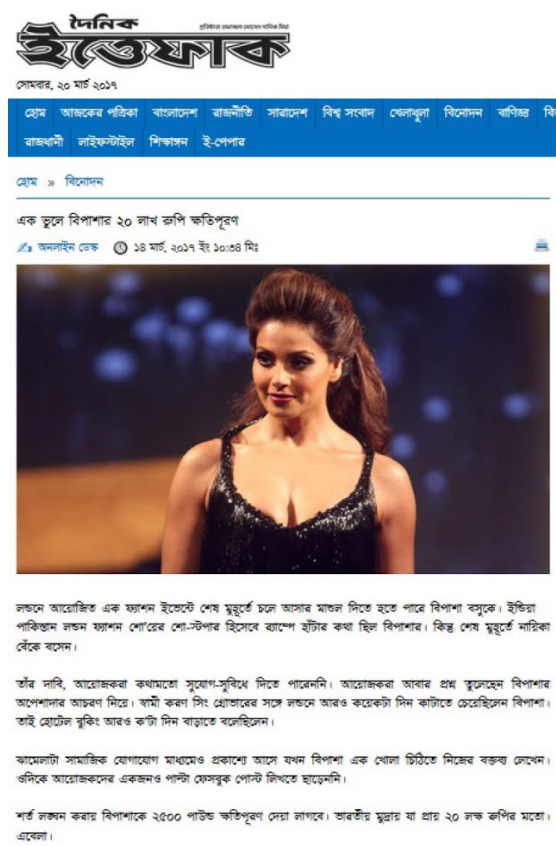

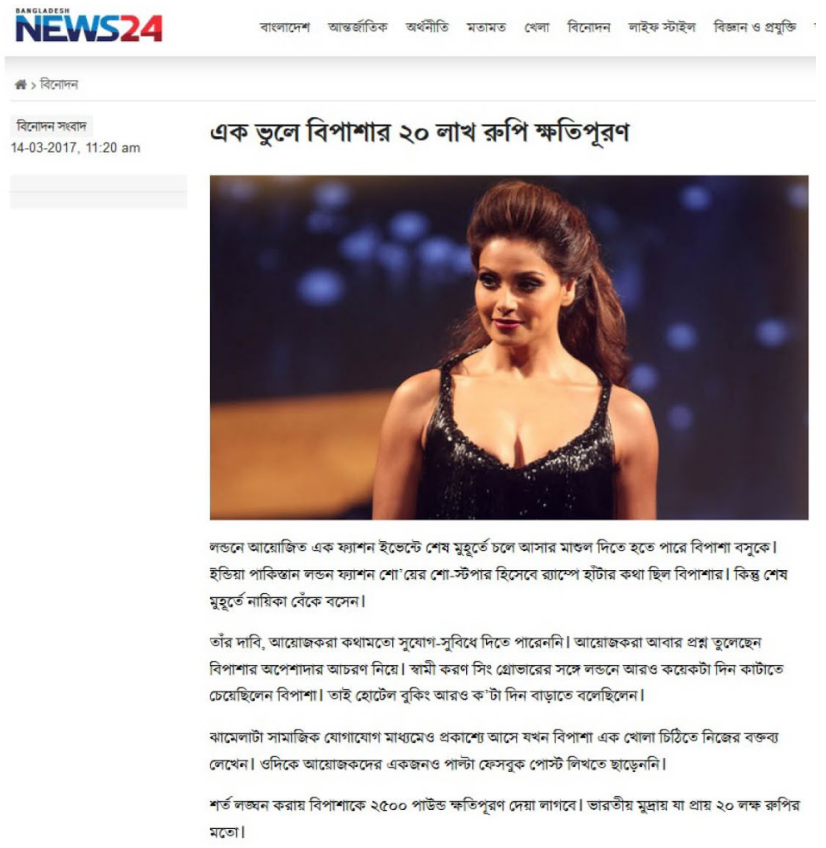

माण।

Figure 2: Example of copying content verbatim. 
on the internet makes it harder to establish effective regulations [12]. In the context of the situation presented in this study suggests the following recommendations enforce the protection of Intellectual Property in the Online News Media of Bangladesh.

\section{Establish a Copyright Monitoring Cell}

During the process of this study, it was observed that the majority of the cases identified were either reported on the social media, discussed in blogs and one of the five cases were reported publicly. To protect their intellectual properties, online news media have to be conscious and vigilant. However, it is equal time, and energy consuming to constantly not only be on the lookout for a content theft but also reach out and take necessary actions to remedy an infringement of copyrights of an online author. Increasingly important is the fact that a collective pressure is due to those media who are trying to run news portals based on copied content while others are investing their hard work, time, skills and money. A copyright monitoring cell in this situation can prove to be significantly effective to mediate infringements on behalf the owner. At the same time, the supervisory body could provide licensing services for those who wish to use others copyrights protected contents.

\section{Comprehensive Media Policy for Fair Competition}

Within the SAARC countries, either organization is working to establish a culture respectful towards Intellectual Property Rights by enhancing knowledge and competencies to protect intellectual property rights, or there is a significant upgradation of the infrastructure to protect intellectual property rights is in the process [13]. Bangladesh too is in great need of such societal renovation developing respect for intellectual properties of others. A comprehensive media policy could be the cornerstone of establishing a culture of protection of intellectual property. Specifically, in the case of online news media, it has become an impending demand of time. With the increased integration of newer technologies in the media industry, appropriate policies are required for developing a field for fair and lawful competition. Existing legal framework is not up to the mark in ensuring a legitimate competition. A comprehensive policy measure shall go a long way to ensure such development in the media sector. Although there have been initiatives to develop communication policies for the online media they are not nearly enough [12] to meet the challenges of the modern integrated arena media to protect copyrights of digital content. There have to be clear media operations guidelines that compliment substantial structural shift to protect intellectual property rights in the digital age.

\section{Develop Necessary Infrastructure to Capacitate Present and Future Requirements}

Bangladesh does not have the technological prowess, strong infrastructure, workforce and adequate resources to ensure fruitful and effective enforcement of the IPRs [14]. Alongside policy, recalibration to protect intellectual property online digital service delivery has to be enhanced. It is high time that copyright offices of Bangladesh are brought under total automation so that copyrights can be registered remotely and more efficiently. A substantial digital database would do wonders to streamline the processes of making copyright claims and as well as remedies in case of infringements. Skilled and tech-savvy human resource development is an absolute must to provide copyright protection in the online news media. Technologically progressed and developed countries with strong intellectual property rights protection are on a continued journey for innovation whereas Bangladesh could not benefit much from the intellectual community because of inadequate IP infrastructures [13]. Until and unless a sufficient infrastructure is established to protect IP Bangladesh is not going to progress regarding technological innovations. Moreover, establishing adequate protection for the digital media might just be the stepping stone of protecting IP rights in all other sectors [15].

\section{Conclusion}

Much has been discussed on the issue of timeliness in the online news media. The fast paced nature of the medium demands fast resolution of issues obstructing its regular pace of operations. Copyrights claims for the online news media require special attention and cannot, in any case, be put through the bureaucratic procedures of litigations. It is highly critical at this time that to protect the sanctity of journalism as a service to the society. Without proper protection for intellectual rights, it is highly unlikely that objective journalism will continue to thrive. Bangladesh in no ways can cross the thresholds of the definitions of a less developed nation to become a developed one without strictly eradicating poor qualities of its media industry. Without proper and timely steps the mushrooming of online media to will continue unchecked like a cancerous cell for the entire nation. Only through fast, easily available and affordable measures to protect the value of intellectual rights the new age of media could accelerate the growth of economies such as ours.

\section{References}

1. Farhi $P$ (2012) Fareed Zakaria suspended by CNN, Time for plagiarism. The Washington Post.

2. Rahman MA (2013) Dhaka Tribune. Retrieved March 16, 2017, from Intellectual property rights in Bangladesh.

3. Khondker BH, Nowshin S (2013) Developing National Intellectual Property Policy for Bangladesh: An Assessment of National Intellectual Property System (Draft). Dhaka: World Intellectual Property Organization (WIPO).

4. Khan MY (2008) A Study of the Copyright Law in England, U.S.A. and Bangladesh.

5. The World Intellectual Property Organization. (2006). Bangladesh: The Copyright Rules.

6. Naznin SM (2011) Protecting Intellectual Property Rights in Bangladesh: An Overview. Bangladesh Research Publications Journals 6: 12-21.

7. Hawlader AA (2007) Enforcement of Copyright Law in Bangladesh. National Seminar and Workshop on Copyright Awareness and Production and Utilisation of Asian Copyright Handbook 49-56.

8. Intellectual Property Association of Bangladesh (2014) IP Digitalization in Bangladesh.

9. Hossain MM (2012) Present Situation of Copyright Protection in Bangladesh Bangladesh Research Publications Journal 7: 99-109.

10. Tuheen SR (2016) The independent. Retrieved March 17, 2017, from Online newspapers: the Bangladesh perspective.

11. bdnews24.com. (2016) bdnews24.com sends letter to Ittefaq demanding apology for using content in copyright violation.

12. risingbd.com. (2016) 1717 online news portals seek for registrations.

13. Chowdhury MS, Hoque S (2013) Online Media Operations (draft) Policy 2012 Review and Evaluation (in Bangla). Social Science Journal, Dhaka University Studies 7: 27-38

14. Uddin MK (2011) Draft Report on Innovation and Intellectual Property Policy and Strategy for Bangladesh. Dhaka: World Intellectual Property Organization (WIPO)

15. Ahmed A (2016) Enforcement of Intellectual Property Rights (IPRS) in Bangladesh: An Appraisal. IOSR Journal of Humanities and Social Science (IOSR-JHSS) 21: 37-46. 